\title{
Isolation and Purification of CP43 and CP47 Photosystem II Proximal Antenna Complexes from Plants
}

\author{
Rafael Picorel, Miguel Alfonso and Michael Seibert
}

\begin{abstract}
A method to isolate and purify CP43 and CP47 pigment-protein complexes from Photosystem (PS) II of higher plants is presented. The method has been developed in spinach, but it may also be valid for other plant species, since there is high PSII core complex homology in all plants. Core complex, obtained from highly-enriched PSII membrane fragments (the extrinsic proteins were previously removed by Tris treatment), is used as starting material. The core complex is first treated with the chaotropic agent, $\mathrm{LiClO}_{4}$, and the nonionic detergent, n-dodecyl $\beta$-D-maltoside. After dialysis against buffer lacking detergent or chaotropic agent, the solubilized material is separated by anion-exchange chromatography using a TSK Toyopearl DEAE 650s column. CP43 complex does not bind to the column under these conditions and elutes along with free pigments and few other contaminants. When the eluate becomes colorless, the column is subjected to a $0-170 \mathrm{mM} \mathrm{LiClO}_{4}$ linear gradient. The main pigment elution band corresponds to the $\mathrm{CP} 47$ complex with some contaminants. To obtain pure preparations of CP43 and CP47 complexes, other chromatographic steps were developed. The CP43 material is passed through a S-Sepharose cation-exchange column at room temperature and then through a Q-Sepharose anion-exchange column. After dialysis, the solution is passed through a new Q-Sepharose anion-exchange column at a different $\mathrm{pH}$. The bound material is eluted with a $10-70 \mathrm{mM} \mathrm{MgSO}_{4}$ linear gradient, and the fractions with a prominent peak at $670 \mathrm{~nm}$ and a clear shoulder at 683 $\mathrm{nm}$ are combined. This constitutes pure CP43 complex. The CP47 material from the first column is dialyzed, loaded onto a new TSK Toyopearl DEAE 650s column, and eluted with a $0-175 \mathrm{mM} \mathrm{LiClO}_{4}$ linear gradient. The fractions with a peak at $674.8 \mathrm{~nm}$ are combined and constitute pure $\mathrm{CP} 47$ complex.
\end{abstract}

Key Words: Ion-exchange chromatography; CP43; CP47; photosystem II; pigmentprotein complexes; purification; spectroscopy.

\section{Introduction}

Photosystem II is a membrane-bound, pigment-protein complex present in all oxygenic photosynthetic organisms, and it is composed of a large number of protein subunits and cofactors. The oxygen-evolving core complex (OECC), an integral part of PSII, is surrounded by distal antenna complexes, including light-harvesting complex (LHCII), chlorophyll protein (CP) 29, CP26, and CP24. It can be isolated from plants, algae, and cyanobacteria; and it is composed of the D1-D2-cytochrome (Cyt) $b_{559}$ reaction center complex (the site of primary charge separation), the CP43 and CP47 proximal antenna complexes, and the 33-kDa extrinsic protein. After Tris- $\mathrm{HCl}$ treatment of PSII-enriched membrane fragments at basic $\mathrm{pH}$, the membrane-bound OECC losses three extrinsic proteins, and with them, the capability of splitting water (i.e., the isolated OECC material lacking the extrinsic proteins is then called core complex). The names of the proximal antenna complexes are derived from the apparent molecular mass, determined by sodium dodecyl sulfate-polyacrylamide gel electrophoresis (SDSPAGE), of the individual polypeptide present in each complex. The CP43 and CP47 complexes are encoded by the chloroplast genes, $p s b C$ and $p s b B$, respectively. 
According to the three-dimensional structure of the OECC from cyanobacteria $(1,2,3)$, CP43 is physically closer to D1 and CP47 to the D2 reaction center polypeptides, respectively. Both proximal antennae most probably function as a conduit for excitation energy transfer between the distal antenna complexes and the reaction center. However, other functions have also been attributed to them, including involvement in the assembly of an active oxygen-evolving complex (4). The purification of native CP43 and CP47 complexes is necessary to assess their physical, chemical, and spectroscopic properties without contamination from other photosynthetic pigments or pigmentprotein complexes. In this Chapter we describe a method to isolate and purify $\mathrm{CP} 43$ and CP47 after disruption of the core complex (isolated directly from Tris-treated PSII membrane fragments) by a combination of a chaotropic agent $\left(\mathrm{LiClO}_{4}\right)$ and a mild detergent (DM), followed by separation using several ion-exchange chromatographic columns. Highly pure pigment-protein complexes result from this procedure.

\section{Materials and Equipment}

1. PS II core complex from spinach (see Notes $\mathbf{1}$ and 2).

2. TSK Toyopearl DEAE 650s, a weak anion-exchange resin.

3. S-Sepharose, a strong cation-exchange resin.

4. Q-Sepharose, a strong anion-exchange resin.

5. A high-speed, refrigerated centrifuge and microfuge.

6. A high-performance liquid chromatography apparatus (HPLC).

7. A reversed-phase liquid chromatography column.

8. Unloaded chromatography columns.

9. $n$-Dodecyl $\beta$-D-maltoside (DM).

10. Buffer 1: $50 \mathrm{mM}$ MES, $\mathrm{pH} 6.0,150 \mathrm{mM} \mathrm{NaCl}$, and $400 \mathrm{mM}$ sucrose.

11. Buffer 2: $20 \mathrm{mM}$ Bis-Tris, $\mathrm{pH}$ 6.0, $4 \mathrm{M} \mathrm{LiClO}_{4}$, and15\% (w/v) DM.

12. Buffer 3: $20 \mathrm{mM}$ Bis-Tris, $\mathrm{pH}$ 6.0.

13. Buffer 4: $20 \mathrm{mM}$ Bis-Tris, $\mathrm{pH} 6.0$, and $0.05 \%(\mathrm{w} / \mathrm{v}) \mathrm{DM}$.

14. Buffer 5: $20 \mathrm{mM}$ Bis-Tris, pH 6.0, $20 \mathrm{mM} \mathrm{NaCl}, 10 \mathrm{mM} \mathrm{MgCl} 2,1.5 \%$ (w/v) taurine, and $0.03 \%(\mathrm{w} / \mathrm{v}) \mathrm{DM}$.

15. Buffer 6: $50 \mathrm{mM}$ Tris-HCl, $\mathrm{pH} 7.8$, and $0.03 \%(\mathrm{w} / \mathrm{v}) \mathrm{DM}$.

\section{Methods}

The basic protocols have been published in Alfonso et al. (5) and Dang et al. (6). All procedures are carried out at $4^{\circ} \mathrm{C}$ in the dark unless otherwise specified.

\subsection{Isolation of PSII core complex}

1. Treat highly-enriched PSII membrane fragments $(60 \mathrm{mg}$ total $\mathrm{Chl})$ from spinach with $0.8 \mathrm{M}$ Tris-HCl, $\mathrm{pH} 8.0$ to remove the three extrinsic proteins associated with $\mathrm{O}_{2}$ evolution (see Notes 1 and 2).

2. Centrifuge at $40.000 \mathrm{xg}$ for $20 \mathrm{~min}$.

3. Resuspend the pellet in buffer 1 at $3 \mathrm{mg} \mathrm{Chl} / \mathrm{mL}$ and obtain good-quality PSII core complex following the method of (7). This method is normally used to isolate OECC. The fact that the PSII membranes are lacking the extrinsic proteins does not affect the ability of this procedure to produce good quality PSII core complex instead of OECC.

4. Mix the Tris-treated PSII membranes with an equal volume of buffer 2, and incubate for 15 min with occasional hand shaking (see Notes 2 and 3 ).

5. Dialyze the solubilized material in $10-\mathrm{kDa}$ molecular cut-off dialysis tubing against buffer 3 for $2 \mathrm{~h}$. 


\subsection{Purification of the CP43 complex}

3.2.1. TSK Toyopearl DEAE 650s, weak anion-exchange chromatography.

1. Load the dialyzed material onto a TSK Toyopearl DEAE 650s weak anionexchange column $(1.6 \times 7.5 \mathrm{~cm})$, previously equilibrated with buffer 4 , at a flow rate of $2 \mathrm{~mL} / \mathrm{min}$.

2. Wash the column with buffer 4 at a flow rate of $1 \mathrm{~mL} / \mathrm{min}$, and collect $1 \mathrm{~mL}$ fractions of the eluate. The eluate contains $\mathrm{CP} 43$, free pigments, and some other contaminants.

3. When the eluate becomes colorless, subject the column to a $0-175 \mathrm{mM} \mathrm{LiClO}_{4}$ linear gradient in buffer 4 at a flow rate of $0.5 \mathrm{~mL} / \mathrm{min}$, and collect $0.5 \mathrm{~mL}$ fractions. The first greenish fractions correspond to some pigment-protein complex contaminants, including CP29, and the main green elution band at around $75 \mathrm{mM} \mathrm{LiCLO}_{4}$ corresponds to CP47 complex.

4. The final elution band comes out at around $125 \mathrm{mM} \mathrm{LiClO}_{4}$, and it contains a mixture of CP47-D1D2Cyt $b_{559}$ and D1D2Cyt $b_{559}$ complexes.

5. The fractions of the main elution band that show a prominent room temperature absorption peak at around $675 \mathrm{~nm}$, and a small absorption band at around $620 \mathrm{~nm}$ (a vibronic band of $\mathrm{Chl} \mathrm{a}$ ) with similar absorbance to that at around $490 \mathrm{~nm}$ (the lowest energy carotenoid band) are collected and dialyzed overnight against buffer 4. This material will be used latter to obtain purified CP47.

\subsubsection{S-Sepharose, strong cation-exchange chromatography}

1. Pass the material that does not bind to the TSK Toyopearl DEAE 650s column through a room-temperature, S-Sepharose column $(1.0 \times 10 \mathrm{~cm})$, equilibrated with buffer 5 .

\subsubsection{Q-Sepharose, strong anion-exchange chromatography}

1. Pass the material that does bind to the S-Sepharose column through a Q-Sepharose column $(1.0 \times 5 \mathrm{~cm})$, equilibrated with buffer 5 .

2. Dialyze the material that does not bind to the column overnight against buffer 6 .

3. Load the dialyzed material onto a fresh Q-Sepharose column, equilibrated with buffer 6 .

4. Wash the column with buffer 6 until the eluate becomes colorless.

5. Elute the green, bound material at a flow rate of $0.5 \mathrm{~mL} / \mathrm{min}$ with a $10-70 \mathrm{mM}$ $\mathrm{MgSO}_{4}$ linear gradient in buffer 6 .

6. Collect $0.5 \mathrm{~mL}$ fractions and combine those with a prominent room temperature absorption peak at $670 \mathrm{~nm}$, a pronounced shoulder at $683 \mathrm{~nm}$ (see Note 4), and an absorption band at $620 \mathrm{~nm}$ that has a lower absorbance than the band at around $490 \mathrm{~nm}$. Subsequently, dialyze the combined fraction pool twice for 1 hour each against $1 \mathrm{~L}$ of buffer 6 .

7. Concentrate the sample with $30-\mathrm{kDa}$ cut-off Amicon Centricon tubes and keep frozen at $-80^{\circ} \mathrm{C}$ (see Note 5). This is purified CP-43 complex,

\subsection{Purification of $C P 47$}

1. Load the dialyzed, impure CP47 material from the first TSK Toyopearl DEAE $650 \mathrm{~s}$ column onto another TSK Toyopearl DEAE $650 \mathrm{~s}$ column $(1.0 \times 5.0 \mathrm{~cm})$.

2. Wash the column with buffer 4 until the eluate is colorless.

3. Apply a 0-175 $\mathrm{mM} \mathrm{LiClO}_{4}$ linear gradient in buffer 4 , and collect $0.5 \mathrm{~mL}$ fractions at a flow rate of $0.5 \mathrm{~mL} / \mathrm{min}$.

4. Take the room-temperature absorption spectrum of each fraction. Discard the 
fractions containing PSII reaction centers (those with a band at $542 \mathrm{~nm}$ ). Pool those with a prominent peak at $674.8 \mathrm{~nm}$ and an absorption band at $620 \mathrm{~nm}$ that has an absorbance similar to that at around $490 \mathrm{~nm}$.

5. Dialyze the pool against buffer 4 and concentrate as convenient using $30-\mathrm{kDa}$ cutoff Amicon Centricon tubes and keep frozen at $-80^{\circ} \mathrm{C}$ (see Note 5). This is purified CP-47.

\subsection{Criteria to assess the quality of the preparations}

1. A rapid and simple method: room-temperature UV-Vis absorption spectra (Fig. 1). A high-quality preparation of CP43 should have a prominent peak at $670 \mathrm{~nm}$ and a distinct shoulder at $683 \mathrm{~nm}$ (see Note 4). The absorption intensity at around 620 $\mathrm{nm}$ due to $\mathrm{Chl} a$ is a little lower than that of the lowest energy carotenoid band at around $490 \mathrm{~nm}$.

A high-quality preparation of CP47 should have a maximum at $674.8 \mathrm{~nm}$, and the absorbance intensity of the $620 \mathrm{~nm}$ band should be similar to that at around 490 nm.

2. Low-temperature absorption and fluorescence spectra.

The low-temperature (4K) absorption spectrum of CP43 shows a prominent peak at $669 \mathrm{~nm}$, a shoulder at around $678 \mathrm{~nm}$, and a small but distinct peak at $683 \mathrm{~nm}$ (i.e., the height of the $683 \mathrm{~nm}$ peak indicates the quality of the CP43 preparation). The low-temperature fluorescence spectrum of pure and native $\mathrm{CP} 43$ should have a single band at $683 \mathrm{~nm}$.

The low-temperature absorption spectrum of CP47 should have multiple bands at around $660,670,677$, and $682 \mathrm{~nm}$ with the maximum peak at $677 \mathrm{~nm}$. The lowtemperature fluorescence spectrum of pure and native $\mathrm{CP} 47$ should have a single band at 693-695 $\mathrm{nm}$.

\subsection{Additional procedures to analyze the quality of the preparations}

1. Pigment analysis by HPLC.

Pigments from CP43 or CP47 preparations can be extracted with $80 \%$ (v/v) cold aqueous acetone by sonicating the suspensions for $1 \mathrm{~min}$. This releases pigments from the protein-detergent complexes, and the extracts are then centrifuged for 5 min in a microfuge (Beckman Microfuge E). The white pellet, containing detergent and denatured protein is dicarded, and the pigment-containing supernatant is injected in a C-18, reversed-phase HPLC column (8). The chromatograms are monitored at $450 \mathrm{~nm}$, and pure preparations show only two main peaks that correspond to Chl $a$ and $\beta$-carotene. The appearance of $\mathrm{Chl} b$ and/or xantophylls is a clear indication of contamination by other pigment-protein complexes.

2. Polypeptide composition.

The polypeptide content of the $\mathrm{CP} 43$ or $\mathrm{CP} 47$ preparations can be analyzed by SDS-PAGE using 12\% (w/v) acrylamide with $4 \mathrm{M}$ urea. Coomassie Brilliant Blue stained gels should show a single band at $43 \mathrm{kDa}$ or $47 \mathrm{kDa}$ for pure CP43 or CP47, respectively.

\section{Notes}

1. Good-quality PSII core complexes are a requisite for obtaining optimal results using the above-described procedures. The absorption spectrum of a good core complex should peak at around 674-675 nm, but cores with a maximum somewhat higher (up to $676 \mathrm{~nm}$ ) are also acceptable for purification of CP43 and CP47 complexes. The exact peak maximum depends on the amount of contaminants that 
are often found in PSII core complex preparations. These contaminants are eliminated after the above-described, successive liquid chromatographic steps.

2. Elimination of the extrinsic proteins from plant PSII membranes by treatment with $0.8 \mathrm{M}$ Tris-HCl, $\mathrm{pH}$ 8.0, improves the yield of the PSII core complex extraction by the method in (7). This treatment also increases somewhat the degree of disruption of the resulting core complex with $\mathrm{LiCLO}_{4}$ and DM.

3. The preparation of buffer containing $4 \mathrm{M} \mathrm{LiClO}_{4}$ must be done at room temperature, and the buffer must be kept at that temperature until use. Lower temperatures result in the precipitation of $\mathrm{LiClO}_{4}$. After mixing one part PSII core complex in buffer 1 (at $4^{\circ} \mathrm{C}$ ) with one part of buffer 2 (at room temperature), the suspension is incubated at $4^{\circ} \mathrm{C}$ for 15 min with occasional hand mixing. All buffers containing DM should be prepared freshly before use.

4. When room-temperature absorption spectra are taken in the $350-750 \mathrm{~nm}$ region, it is helpful to examine expanded spectra in the $600-750 \mathrm{~nm}$ region. The CP43 shoulder at $683 \mathrm{~nm}$ is easier to see under these conditions (Fig. 1). If it cannot be seen, the CP43 preparation is of poor quality.

5. $\mathrm{CP} 43$ and $\mathrm{CP} 47$ complexes are stable at $-80^{\circ} \mathrm{C}$ for a long time, and they can even be thawed and refrozen a few times without significant changes in their spectroscopic properties.

\section{Acknowledgments}

This work was supported by the Ministry of Science and Innovation of Spain (Grants BFU2005-07422-C02-01 and AGL2008-00377) to R. P., and in the USA by the Chemical Sciences, Geosciences, and Biosciences Division, Office of Basic Energy Sciences, US Department of Energy (M.S.).

\section{References}

1. Kayami, N. and Shen, J. R. (2003) Crystal structure of oxygen-evolving photosystem II from Thermosynechococcus vulcanus at 3.7 Á resolution. Proc. Natl. Acad. Sci. USA 100, 98-103.

2. Loll, B., Kern, J., Zouni, A. and Biesiadka, J. (2005) Towards complete cofactors arramgement in the $3.0 \AA$ resolution structure of photosystem II. Nature 438, 10401044.

3. Guskov, A., Kem, J., Gabdulkhakov, A., Broser, M., Zouni, A. and Saenger W. (2009) Cyanobacterial photosystem II at 2.9-Á resolution and the role of quinones, lipids, channels and chloride. Nature Structural Biology 16(2), 334-342.

4. Bricker, T. M., and Frankel, L. K. (2002) The structure and function of CP47 and CP43 in photosystem II. Photosynth. Res. 72, 131-146.

5. Alfonso, M., Montoya, G., Cases, R., Rodríguez, R. and Picorel, R. (1994) Core antenna complexes, CP43 and CP47, of higher plant photosystem II. Spectral properties, pigment stoichiometry, and amino acid composition. Biochemistry 33, 10494-10500.

6. Dang, N. C., Zazubovich, W., Reppert, M. Neupane, B., Picorel, R., Seibert, M. and Jankowiak, R. (2008) The CP43 proximal antenna complex of higher plant photosystem II revisited: Modeling and hole burning study, I. J. Phys. Chem. B 112, 9921-9933.

7. Ghanotakis, D. F., Demetriou, D. M. and Yocum, C. F. (1987) Isolation and characterization of an oxygen-evolving photosystem II reaction center core preparation and a $28 \mathrm{kDa}$ Chl-a-binding protein. Biochim. Biophys. Acta 891, 1521 . 
8. Larbi, A., Abadía, A. Morales, F. and Abadía, J. (2004) Fe resupply to Fe-deficient sugar beet plants leads to rapid changes in the violaxhantin cycle and other photosynthetic characteristics without significant de novo chlorophyll síntesis.

Photosynth. Res. 79, 59-6

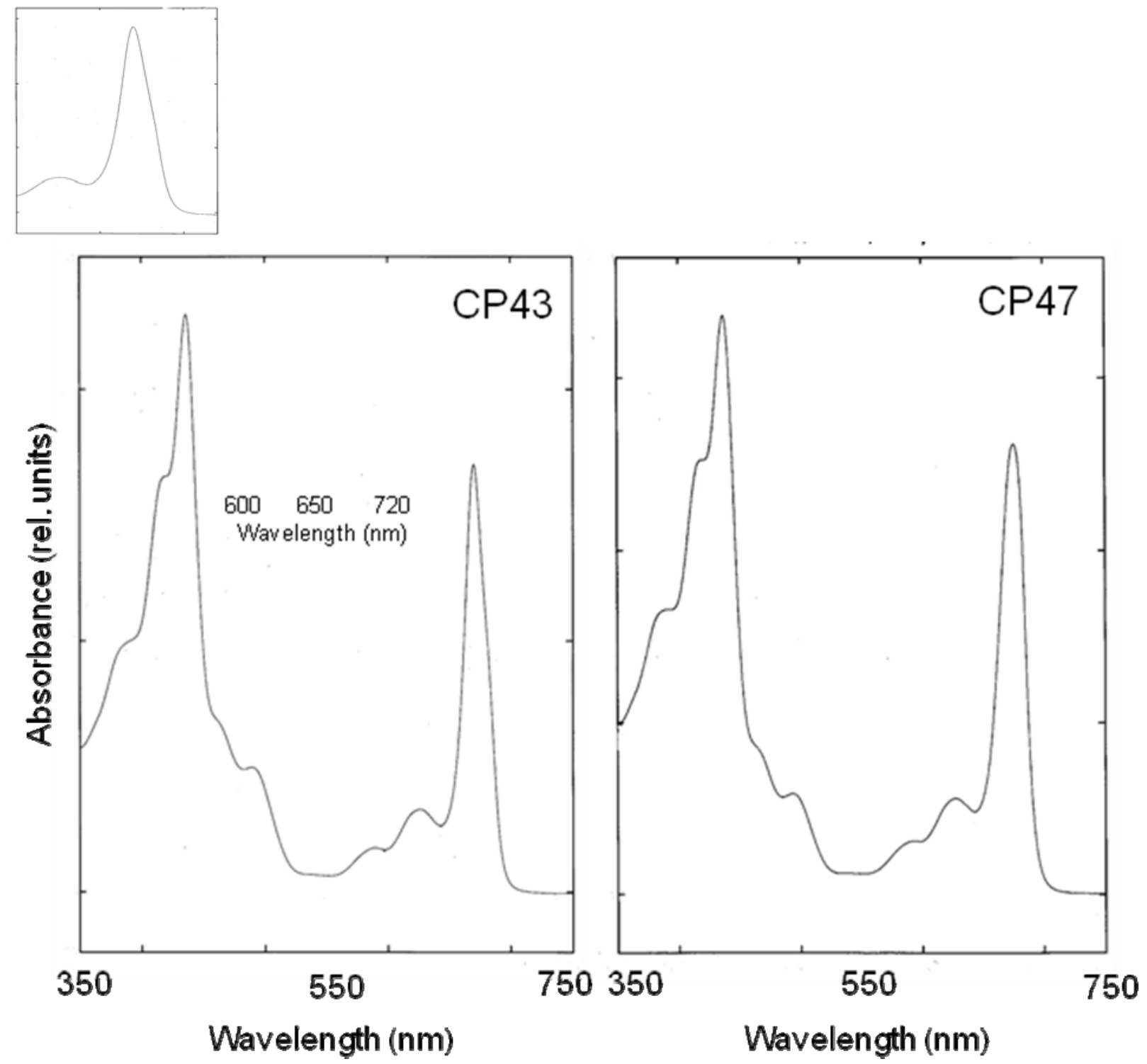

